\title{
Genetic differentiation and geographical Relationship of Asian barley landraces using SSRs
}

\author{
Rehan Naeem ${ }^{1}$, Lynn Dahleen ${ }^{2}$ and Bushra Mirza ${ }^{1}$ \\ ${ }^{\text {I}}$ Faculty of Biological Sciences, Department of Biochemistry, Quaid-i-Azam University, \\ Islamabad, Pakistan. \\ ${ }^{2}$ USDA-ARS, Cereal Crops Research Unit, Fargo, ND, USA.
}

\begin{abstract}
Genetic diversity in 403 morphologically distinct landraces of barley (Hordeum vulgare L. subsp. vulgare) originating from seven geographical zones of Asia was studied using simple sequence repeat (SSR) markers from regions of medium to high recombination in the barley genome. The seven polymorphic SSR markers representing each of the chromosomes chosen for the study revealed a high level of allelic diversity among the landraces. Genetic richness was highest in those from India, followed by Pakistan while it was lowest for Uzbekistan and Turkmenistan. Out of the 50 alleles detected, 15 were unique to a geographic region. Genetic diversity was highest for landraces from Paki$\operatorname{stan}(0.70 \pm 0.06)$ and lowest for those from Uzbekistan $(0.18 \pm 0.17)$. Likewise, polymorphic information content (PIC) was highest for Pakistan $(0.67 \pm 0.06)$ and lowest for Uzbekistan $(0.15 \pm 0.17)$. Diversity among groups was $40 \%$ compared to $60 \%$ within groups. Principal component analysis clustered the barley landraces into three groups to predict their domestication patterns. In total $51.58 \%$ of the variation was explained by the first two principal components of the barley germplasm. Pakistan landraces were clustered separately from those of India, Iran, Nepal and Iraq, whereas those from Turkmenistan and Uzbekistan were clustered together into a separate group.
\end{abstract}

Key words: cluster analysis, genetic diversity, geographical differentiation, Hordeum vulgare, principal component analysis.

Received: April 28, 2010; Accepted: December 9, 2010.

Cultivated barley is one of the oldest known domesticated crops suggested to have multiple origins (MolinaCano et al., 2005). Archaeological studies indicate that it was first domesticated in the Fertile Crescent about 10,000 yeas ago (Zohary and Hopf, 1993). This is assumed to have taken place from two-rowed wild barley Hordeum vulgare L. subsp. spontaneum in the Near East (Harlan and Zohary, 1966). The research of Badr et al. (2000) supported a monophyletic-barley origin, based on allele frequencies at 400 polymorphic loci. Tibetan wild barley is the proposed progenitor of cultivated barley in the Oriental region (Aberg, 1940). Nevertheless, domestication also occurred in other parts of the world, apart from the Fertile Crescent (Molina-Cano et al., 1999). Recently, Morrell and Clegg (2007) proposed that the domestication of the cultivated form started in the Indus valley, at the site of Mehrgarh (Pakistan) at about 7,000 B.C.

Microsatellite markers have been regularly used to evaluate domestication patterns and genetic relationships among barley landraces. Microsatellites, also known as simple sequence repeats (SSRs), are short (1-6 bp) tandemly repeated DNA sequences that are highly polymor-

Send correspondence to Lynn Dahleen. USDA-ARS, NCSL, 1605 Albrecht Blvd. Fargo, ND, 58102, USA. E-mail: lynn.dahleen@ars.usda.gov. phic as a result of frequent variation in the number of times the core sequence is repeated (Tautz, 1989). SSR technology is useful for evaluating genetic diversity and phylogenetic relationships within different populations of the genus Hordeum (Saghai-Maroof et al., 1994).

In the present investigation, 403 landraces of cultivated barley, originally collected from Pakistan, India, Iran, Nepal, Iraq, Turkmenistan, and Uzbekistan, were assessed with a panel of mapped SSRs to estimate regional genetic diversity, phylogenetic relationships and population structure. The 403 six-rowed and two-rowed landraces were chosen for genetic characterization according to their origin, spike characteristics and growth habits (Table 1). Representative numbers of landraces from each eco-geographical population were collected, except for Uzbekistan, since these were underrepresented in the germplasm bank. The seeds were provided by the Institute of Plant Genetic Resource Program, N.A.R.C., Islamabad.

Genomic DNA was isolated from young barley leaves of 403 individual plants (one representing each landrace) using the $\mathrm{CTAB}$ procedure of Doyle and Doyle (1990), with certain modifications, including treatment with RNase A at $37^{\circ} \mathrm{C}$ for $45 \mathrm{~min}$. The DNA was purified by phenol: chloroform: isoamyl alcohol extraction and diethyl ether treatment. The final pellet was dissolved in 
Table 1 - Qualitative characteristics of 403 barley landraces used for studying diversity

\begin{tabular}{|c|c|c|c|c|c|c|c|}
\hline \multirow[t]{2}{*}{ Origin } & \multirow[t]{2}{*}{ Sample size } & \multicolumn{2}{|c|}{ Spike type } & \multicolumn{2}{|c|}{ Hull type } & \multicolumn{2}{|c|}{ Awns } \\
\hline & & 2-rowed & 6-rowed & Covered & Hulless & Awned & Awnless \\
\hline Pakistan & 160 & 2 & 158 & 137 & 23 & 159 & 1 \\
\hline India & 76 & 18 & 58 & 70 & 6 & 70 & 6 \\
\hline Iran & 56 & 19 & 37 & 56 & 0 & 56 & 0 \\
\hline Nepal & 51 & 9 & 42 & 49 & 2 & 45 & 6 \\
\hline Iraq & 38 & 17 & 21 & 36 & 2 & 37 & 1 \\
\hline Turkmenistan & 17 & 6 & 11 & 14 & 3 & 17 & 0 \\
\hline Uzbekistan & 5 & 2 & 3 & 2 & 3 & 4 & 1 \\
\hline
\end{tabular}

Tris-EDTA buffer. The DNA was diluted with deionized water to obtain a working concentration of $25 \mathrm{ng} / \mu \mathrm{L}$ and the quality analyzed by $1 \%$ agarose gels.

The landraces were genotyped using seven mapped barley SSRs, one for each chromosome (Table 2). The SSR marker on chromosome $3 \mathrm{H}$ was located in a region of medium recombination (1.0-4.4 Mb/cM), whereas the other six SSRs were located in regions of high recombination $(<1.0 \mathrm{Mb} / \mathrm{cM}$; Künzel et al., 2000). The SSR assay followed the procedures of Ramsay et al. (2000), with some modifications, in $25 \mu \mathrm{L}$ of reaction solutions containing $1 \mathrm{x}$ reaction buffer, $100 \mathrm{ng}$ of genomic DNA, $1 \mathrm{U}$ Taq polymerase (Fermentas Life Sciences, Glen Burnie, MD, USA), $0.15 \mathrm{mM} \mathrm{dNTP}$, and $0.2 \mu \mathrm{M}$ of each primer. Amplification was carried out in a thermal cycler (T1, Biometra, Goettingen, Germany) under the following condition: $94{ }^{\circ} \mathrm{C}$ for $5 \mathrm{~min}, 35$ cycles of $94{ }^{\circ} \mathrm{C} 30 \mathrm{~s}$, annealing $1 \mathrm{~min}, 72{ }^{\circ} \mathrm{C}$ $1 \mathrm{~min}$, and a final extension of $10 \mathrm{~min}$ at $72{ }^{\circ} \mathrm{C}$. Both annealing temperature and $\mathrm{MgCl}_{2}$ concentration depended on the primer pair (Ramsay et al., 2000; Macaulay et al., 2001). Polymorphism was detected under UV light after running on $6 \%$ PAGE and staining with ethidium bromide $(0.5 \mu \mathrm{g} / \mathrm{mL})$.
The alleles of each SSR locus were sized (bp) with reference to a known size-standard (O-RangeRuler 20 bp DNA ladder, Fermentas), followed by transformation to binary codes, as presence (1) or absence (0) of the respective fragment size, based on electrophoretic mobility using the procedure of Pau and Southern (1982). Allele frequencies, genetic diversities and homogeneity of allele frequencies were calculated. The number of alleles per locus was counted as the combination of polymorphic bands (Struss and Plieske, 1998). Estimates of the gene diversity index $(\mathrm{H})$, the proportion of polymorphic loci $(\mathrm{P})$, and the mean number of alleles per locus (A) were calculated for each SSR locus and population. Polymorphism information content (PIC) was calculated for each SSR, according to Weber (1990). The genetic diversity index $(D I)$ was estimated as the mean genetic diversity over the loci and adjusted for sample size, according to Nei (1978):

$$
D I=2 n_{a}\left(1 / n_{1} \Sigma\left(1-\Sigma x_{i j}^{2}\right)\right) /\left(2 n_{a}-1\right)
$$

where $x_{i j}$ is the frequency of the $i^{\text {th }}$ allele of locus $j, n_{1}$ is the number of genetic loci and $n_{a}$ the number of landraces. All the calculations described above were carried out using the software POPGENE version 1.32 (Yeh et al., 1999). The distribution of variability between and within groups was calculated according to Nei (1973) for each microsatellite

Table 2 - Total number of alleles and unique alleles for mapped SSR markers in different barley groups.

\begin{tabular}{|c|c|c|c|c|c|c|c|c|}
\hline \multirow[t]{2}{*}{ Locus $\dagger$} & \multirow[t]{2}{*}{ Chrom. } & \multicolumn{7}{|c|}{ Number of alleles } \\
\hline & & Pakistan & India & Iran & Nepal & Iraq & Turkmenistan & Uzbekistan \\
\hline Bmag0382 & $1 \mathrm{H}$ & $4(2)^{*}$ & 3 & $4(1)^{*}$ & 3 & $4(1)^{*}$ & 2 & 2 \\
\hline HVM54 & $2 \mathrm{H}$ & $5(3) *$ & 5 & 5 & 3 & 3 & 4 & 1 \\
\hline Bmac0023 & $3 \mathrm{H}$ & $5(2)^{*}$ & $7(1)^{*}$ & $5(1)^{*}$ & 5 & 4 & 3 & 2 \\
\hline Bmag0490 & $4 \mathrm{H}$ & 4 & 5 & 4 & 4 & 3 & 3 & 2 \\
\hline HvLOX & $5 \mathrm{H}$ & $4(1)^{*}$ & $6(1)^{*}$ & $4(1)^{*}$ & 4 & $3(1)^{*}$ & 2 & 1 \\
\hline Bmag0500 & $6 \mathrm{H}$ & 3 & 4 & 4 & 1 & 2 & 1 & 1 \\
\hline HVID & $7 \mathrm{H}$ & 4 & 5 & 3 & 5 & 3 & 4 & 2 \\
\hline Total & & 29 & 35 & 29 & 25 & 22 & 19 & 11 \\
\hline
\end{tabular}

*Unique alleles.

$\dagger$ Markers on chromosomes 1H, 2H and 5H from Macaulay et al. (2001), the remainder from Ramsay et al. (2000). 
locus. The total observed diversity estimate $(H \mathrm{~T})$ was partitioned into within-group diversity $(H \mathrm{~S})$ and between-group diversity $(D \mathrm{ST})$ components, where $H \mathrm{~T}=H \mathrm{~S}+D \mathrm{ST}$. Gene diversity between groups, in relation to total population diversity, was expressed as $G \mathrm{ST}=D \mathrm{ST} / H \mathrm{~T}$. Principal Component Analysis (PCA) was applied to allele frequencies and implemented with the software package SPSS 11 (SPSS Inc., Chicago, IL, USA), so as to obtain a graphic representation of the relationship structure among the different barley groups.

Allelic diversity was evident in all the seven groups of lines, with most markers detecting two or more alleles per group (Table 2). The main exception was the small group of five lines from Uzbekistan, in which three of the markers revealed only one allele. The Indian group presented the highest number of alleles for the seven markers (Table 2), even though the Pakistani had more than twice as many lines. Allelic diversity in the Pakistani and Iranian groups was similar, although unique alleles were more common in the Pakistani. As expected, groups with the fewest members had the fewest alleles. Allelic diversity also varied among the seven markers tested. The highest number (11) of alleles was detected with the chromosome $3 \mathrm{H}$ marker, whereas only 5 were with chromosome $4 \mathrm{H}, 6 \mathrm{H}$ and $7 \mathrm{H}$ markers in all the 403 lines tested. Furthermore, the latter three revealed no unique group-specific allele. Thirty percent of the alleles were unique to a location.

Allele size diversity, across all the barley accessions, ranged from $26 \mathrm{bp}$ for $\mathrm{Bmag} 0500$ on chromosome $6 \mathrm{H}$ to $69 \mathrm{bp}$ for HvLOX on chromosome 5H (Table S1), the largest size differences by markers generally occurring in the groups with the highest number of alleles. Overall allele frequency ranged from 0.00 to 1.00 . In all the groups, except the Pakistani, there was at least one landrace with a unique marker phenotype. In the latter, the lowest number of landraces with the same marker genotype was five (Bmag0023, $120 \mathrm{bp}$ allele). The most frequent allele in the Pakistani group (Bmag0500, 67 bp allele) was present in only $49 \%$ of the lines, whereas in the others, maximum allele frequency ranged from $62 \%-100 \%$.

Polymorphism-information content for the seven markers (Table S2) varied from 0.45 (Bmag0500, 6H) to 0.66 (Bmag0023, 3H), with an average of 0.58. Measurements of genetic richness (Table 3 ) followed the same pattern as the number of alleles (Table 3), with India having the highest and Uzbekistan the lowest. Genetic diversity was the highest in Pakistan and India, and the lowest in
Uzbekistan. These measurements showed significant differences among the groups, although standard deviation increased to more than half the mean value as the size of the group decreased. The diversity index was not a useful measurement for this material, as standard deviations were mostly higher than mean values. Total gene diversity $(\mathrm{Ht})$ across mapped SSR markers was 0.68 . Within-group diversity $(\mathrm{Hs}=0.41)$ was substantially higher than among population diversity ( $\mathrm{Dst}=0.27)$.

Cluster analysis divided the 403 lines into ten groups (Figure 1, Table S3). The landraces from Pakistan were divided into five clusters, not always in accordance with their regional origins. Thus, clusters V and VIII were solely composed of Pakistani landraces, whereas clusters III, IV, and $\mathrm{X}$ all had large numbers of landraces from this country. The Indian landraces were spread across seven clusters, with more lines in clusters III, VI, and VII than in the remainder. Most Iranian landraces were in clusters IX and VI, with only one in cluster VII and three in cluster X, whereas most from Nepal were in cluster II, most from Iraq in cluster I, and most of the Turkmenistani and Uzbekistani landraces in cluster IV.

Principal component analysis based on allele frequencies among the groups across mapped SSR markers clustered the barley landraces into three groups (Figure S1). All told, $51.58 \%$ of the variation could be attributed to the first two principal components, $33.31 \%$ to the first and $18.27 \%$ to the second. Group 1 was comprised of accessions belonging exclusively to Pakistan, group 2 to India, Iran, Nepal and Iraq, and group 3 only to Turkmenistan and Uzbekistan.

The estimation of genetic diversity is important for the conservation of germplasm. The seven SSRs analyzed in the present study were located in high-recombination chromosomal regions, detecting 50 alleles in the 403 lines including 15 that were unique to a geographic group. Allelic diversity is essential for revealing the potential of germplasm for further conservation studies and plant breeding. The Asian germplasm in our study presented a similar range in number of alleles and alleles per locus, to that detected in previous studies of cultivated barley (Becker and Heun, 1995; Struss and Plieske, 1998; Ivandic et al., 2002; Matus and Hayes, 2002; Sjakste et al., 2003; Hamza et al., 2004; Feng et al., 2006; Malysheva-Otto et al., 2006; Yahiaoui et al., 2008). In general, as the number of lines included in a diversity study increased, so did the number of alleles/locus $(\mathrm{r}=.579, \mathrm{p}=.0793)$. As more

Table 3 - Genetic richness, genetic diversity, and diversity index for different barley groups across mapped SSR markers.

\begin{tabular}{|c|c|c|c|c|c|c|c|c|}
\hline Parameter & Pakistan & India & Iran & Nepal & Iraq & Turkmenistan & Uzbekistan & Total \\
\hline Genetic richness & $4.14 \pm 0.10$ & $5.00 \pm 0.18$ & $4.14 \pm 0.10$ & $3.57 \pm 0.20$ & $3.14 \pm 0.10$ & $2.71 \pm 0.16$ & $1.57 \pm 0.08$ & $7.14 \pm 0.33$ \\
\hline Genetic diversity & $0.70 \pm 0.06$ & $0.67 \pm 0.09$ & $0.56 \pm 0.08$ & $0.52 \pm 0.26$ & $0.33 \pm 0.16$ & $0.55 \pm 0.39$ & $0.18 \pm 0.17$ & $0.77 \pm 0.08$ \\
\hline Diversity index & $0.10 \pm 0.08$ & $0.09 \pm 0.06$ & $0.08 \pm 0.09$ & $0.07 \pm 0.08$ & $0.05 \pm 0.26$ & $0.08 \pm 0.16$ & $0.03 \pm 0.39$ & $0.11 \pm 0.01$ \\
\hline
\end{tabular}




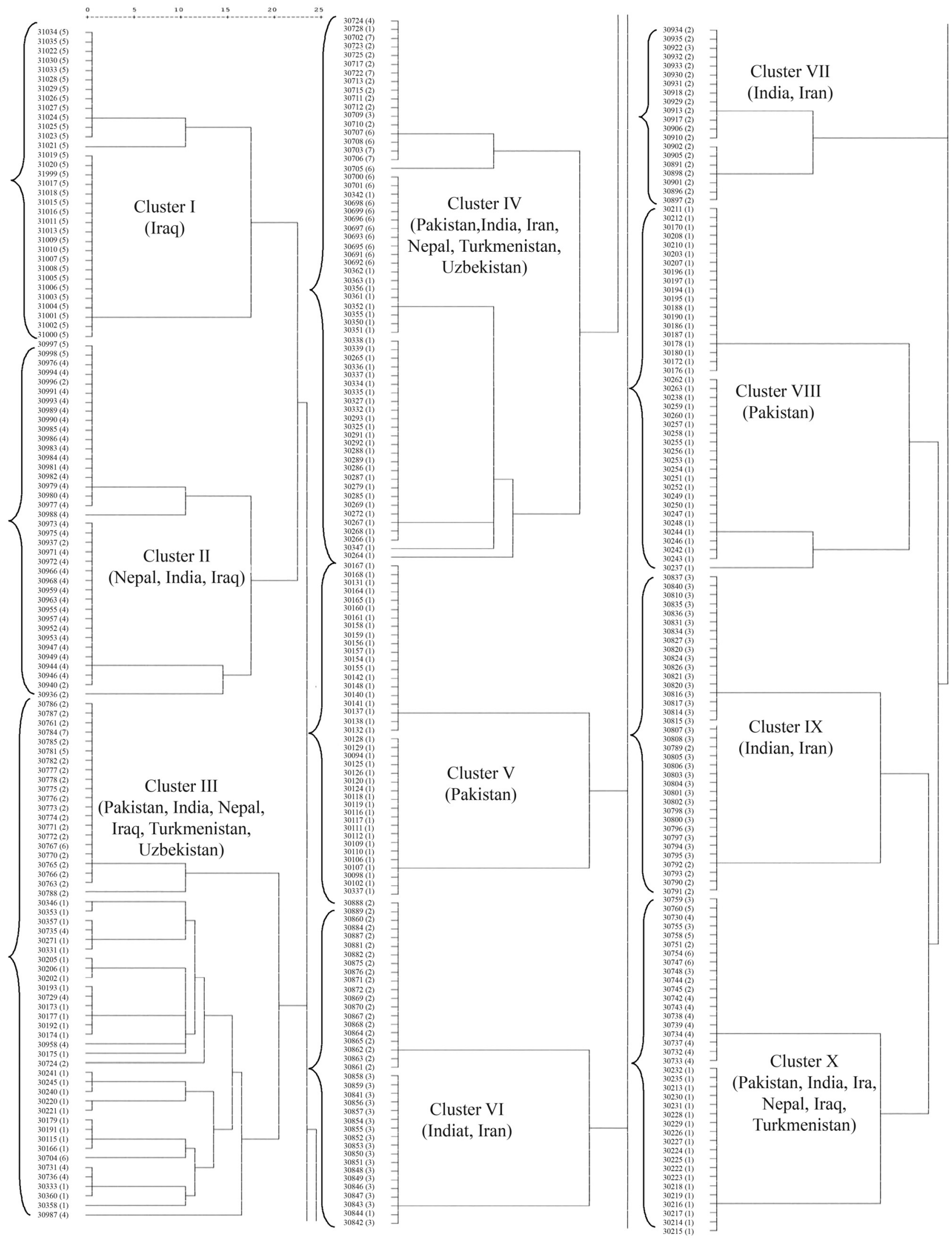

Figure 1 - Dendogram obtained through cluster analysis of the barley landraces on the basis of allele frequencies across mapped SSR markers. Cluster $\mathrm{I}=$ 33 barley accessions, Cluster II $=38$, Cluster III $=55$, Cluster IV $=63$, Cluster V $=39$, Cluster VI $=38$, Cluster VII $=20$, Cluster VIII $=41$, Cluster IX $=38$ Cluster $\mathrm{X}=38$. Accessions in each cluster are listed in Table $\mathrm{S} 3$. 
markers were tested, more alleles were detected $(r=.758$, $\mathrm{p}=0.011)$. Diversity in our survey of 403 landraces from seven regions of Asia was similar to that in 65 naked barley accessions (Feng et al., 2006), and the 163 wild barley landraces and old cultivars tested by Struss and Plieske (1998).

Several studies, including this one, have identified high frequencies of alleles that were unique to a specific region or group of genotypes. We found that $30 \%$ of the alleles were specific for landraces from a single country. Similar studies (Matus and Hayes, 2002; Feng et al. 2006; Yahiaoui et al., 2008) detected 15.7\%-52\% unique alleles in $H$. vulgare specific to a germplasm group. Matus and Hayes (2002) suggested that the presence of so many unique alleles could indicate a relatively high rate of mutation at SSR loci. Unique alleles may be diagnostic of particular inbred lines or for genotype-specific regions of the genome (Senior et al., 1998). The occurrence of a high number of unique alleles in the present study was an indication of the diversity present in this Asian germplasm, as well as its potential as a reservoir of novel alleles required for crop improvement.

Nevo (1998) showed that allelic distribution at microsatellite loci is non-random and associated with habitats. He suggested that populations dwelling in drier habitats have higher genetic diversities at microsatellite loci. Chen et al. (2006) partitioned the total diversity of each locus into average diversity within and among zones. Of the total genetic diversity, $17 \%$ was attributable to differences among and $83 \%$ to differences within the zones. We also found more variability within groups $(60 \%)$ than between groups $(40 \%)$.

Ecogeographical diversity analysis is typically applied to identify "centers of diversity". However, these centers can change over time, as breeding and germplasm exchange continues (Peeters, 1988). The landraces evaluated in this study belong to the Mediterranean (India, Pakistan), Mid-Asian (Iran, Iraq, Turkmenistan, Uzbekistan) and East Asian (Nepal; Knüpffer et al., 2003) Centers. Peeters (1988) evaluated 12 qualitative and 18 quantitative traits in several thousand accessions from around the world. Mean diversity in their germplasm samples was highest in the Indian lines and lowest in the Nepalese. The mean diversity in germplasm from Iran and Pakistan was similar and intermediate to that from India and Nepal. In our study, the same pattern of genetic richness was apparent (Table 3), thereby indicating that the seven SSR markers used gave a reliable representation of the diversity in these lines.

According to principal component analysis (PCA), the barley landraces could be clustered into three groups, Pakistan in one, India, Iran, Nepal and Iraq in a second, and Turkmenistan and Uzbekistan in a third. Genetic distances indicated greater similarity of Iranian, Nepalese and Iraqi landraces with those from Pakistan and India than with those from Turkmenistan and Uzbekistan. Clustering based on individual landraces reflected the results of group PCA, with the Pakistani landraces clustering separately from those originating from other countries. These results are in agreement with Ordon et al. (1997), who observed a clear differentiation between East Asian and German cultivars. Similarly, Hamza et al. (2004) clearly differentiated barley genotypes by UPGMA, according to their geographic regions, row number and end use. In another report, Feng et al. (2006) revealed the genetic relationships of 65 accessions collected from different regions in China. They observed that at a genetic similarity level of about 0.76 , the accessions were clearly clustered into two large groups, all the Tibetan accessions being located in one cluster and those from Qinghai and Ganzi in a second.

In conclusion, landraces from Pakistan had a high frequency of unique alleles (8/29) and formed a separate group by principle component analysis. Turkmenistan and Uzbekistan landraces grouped together and were distinct from the landraces from the other five countries. Landraces from India showed the highest genetic richness, with the most alleles for the seven SSR markers. Overall, our SSR survey of 403 Asian landraces revealed high levels of allelic variation that could be exploited for barley improvement.

\section{References}

Aberg E (1940) The taxonomy and phylogeny of Hordeum L. sect. Cerealia Ands., with special reference to Tibetan barleys. Symbolae Botan Upsalienses 4:1-156.

Badr A, Müller K, Schäfer-Pregl R, El-Rabey H, Effgen S, Ibrahim HH, Pozzi C, Rohde W and Salamini F (2000) On the origin and domestication history of barley (Hordeum vulgare). Mol Biol Evol 17:499-510.

Becker J and Heun M (1995) Barley microsatellites: Allele variation and mapping. Plant Mol Biol 27:835-845.

Chen X, Guo S, Chen D, Liu P, Jia X and Sun L (2006) Assessing genetic diversity of Chinese cultivated barley by STS markers. Genet Resour Crop Evol 53:1665-1673.

Doyle JJ and Doyle JL (1990) Isolation of plant DNA from fresh tissue. Focus 12:13-15.

Feng ZY, Zhang LL, Yi-Zhang and Hong-Qing L (2006) Genetic diversity and geographical differentiation of cultivated six rowed naked barley landraces from the Qinghai-Tibet plateau of China detected by SSR analysis. Genet Mol Biol 29:230-238.

Hamza S, Hamida WB, Rebai A and Harrabi M (2004) SSR-based genetic diversity assessment among Tunisian winter barley and relationship with morphological traits. Euphytica 135:107-118.

Harlan JR and Zohary D (1966) Distribution of wild wheats and barley. Science 153:1074-1080.

Ivandic V, Hackett CA, Nevo E, Keith R, Thomas WTB and Forster BP (2002) Analysis of simple sequence repeats (SSRs) in wild barley from the Fertile Crescent: Associations with ecology, geography and flowering time. Plant Mol Biol 48:511-527.

Knüpffer H, Terentyeva I, Hammer K, Kovaleva O and Sato K (2003) Ecogeographical diversity-a Vavilovian approach. In: Von-Bothmer R, Van-Hintum T, Knüpffer H and Sato K 
(eds) Diversity in Barley (Hordeum vulgare). Elsevier, Amsterdam, pp 53-76.

Künzel G, Korzun L and Meister A (2000) Cytologically integrated physical restriction fragment length polymorphism maps for the barley genome based on translocation breakpoints. Genetics 154:397-412.

Macaulay M, Ramsay L, Powell W and Waugh R (2001) A representative, highly informative 'genotyping set' of barley SSRs. Theor Appl Genet 102:801-809.

Malysheva-Otto LV, Ganal MW and Roder MS (2006) Analysis of molecular diversity, population structure and linkage disequilibrium in a worldwide survey of cultivated barley germplasm (Hordeum vulgare L.). BMC Genetics 7:e6.

Matus IA and Hayes PM (2002) Genetic diversity in three groups of barley germplasm assessed by simple sequence repeats. Genome 45:1095-1106.

Molina-Cano JL, Moralejo MIE and Romagosa I (1999) Further evidence supporting Morocco as a centre of origin of barley. Theor Appl Genet 98:913-918.

Molina-Cano JL, Russell JR, Moralejo MA, Escacena JL, Arias G and Powell W (2005) Chloroplast DNA microsatellite analysis supports a polyphyletic origin for barley. Theor Appl Genet 110:613-619.

Morrell PL and Clegg MT (2007) Genetic evidence for a second domestication of barley (Hordeum vulgare) east of the Fertile Crescent. Proc Natl Acad Sci USA 104:3289-3294.

Nei M (1973) Analysis of gene diversity in subdivided populations. Proc Natl Acad Sci USA 70:3321-3323.

Nei M (1978) Estimation of average heterozygosity and genetic distance from a small number of individuals. Genetics 89:583-590.

Nevo E (1998) Molecular evolution and ecological stress at global, regional and local scales: The Israeli perspective. J Exp Zool 282:95-119.

Ordon F, Schimann A and Friedt W (1997) Assessment of the genetic relatedness of barley accessions (Hordeum vulgare L.) resistant to soil-borne mosaic-inducing viruses (BaMMV, BaYMV, BaYMV-2) using RAPDs. Theor Appl Genet 94:325-330.

Pau G and Southern EM (1982) Electrophoresis of DNA. In: Rickwood D and Hames BD (eds) Gel Electrophoresis of Nucleic Acids: A Practical Approach. IRL Press Ltd, Oxford and Washington DC, pp 39-75.

Peeters JP (1988) The emergence of new centres of diversity: evidence from barley. Theor Appl Genet 76:17-24.

Ramsay L, Macaulay M, Ivanissevich SD, Maclean K, Cardle L, Fuller J, Edwards KJ, Tuvesson S, Morgante M, Massari A et al., (2000) A simple sequence repeat-based linkage map of barley. Genetics 156:1997-2005.

Saghai-Maroof MA, Biyashev RM, Yang GP, Zhang Q and Allard RW (1994) Extraordinarily polymorphic microsa- tellite DNA in barley: Species diversity, chromosomal locations, and population dynamics. Proc Natl Acad Sci USA 91:5466-5470.

Senior ML, Murphy JP, Goodman MM and Stuber CW (1998) Utility of SSRs for determining genetic similarities and relationships in maize using an agarose gel system. Crop Sci 38:1088-1098.

Sjakste TG, Rashal I and Roder MS (2003) Inheritance of microsatellites alleles in pedigrees of Latvian barley and related European ancestors. Theor Appl Genet 107:539-549.

Struss D and Plieske J (1998) The use of microsatellite markers for detection of genetic diversity in barley populations. Theor Appl Genet 97:308-315.

Tautz D (1989) Hypervariability of simple sequences as a general source for polymorphic DNA markers. Nucleic Acids Res 17:6463-6471.

Weber JL (1990) Informativeness of human $(d C-d A)_{n}(d G-d T)_{n}$ polymorphisms. Genomics 7:524-530.

Yahiaoui S, Igartua E, Moralejo M, Ramsay L, Molina-Cano JL, Ciudad FJ, Lasa JM, Gracia MP and Casas AM (2008) Patterns of genetic and eco-geographical diversity in Spanish barleys. Theor Appl Genet 116:271-282.

Yeh FC, Yang RC, Boyle TBJ, Ye ZH and Mao JX (1999) POPGENE, The user-friendly shareware for population genetic analysis. Molecular Biology Biotechnology Centre, University of Alberta Canada.

Zohary D and Hopf M (1993) Domestication of plants in Old World. The origin and spread of cultivated plants in West Asia, Europe and the Nile Valley. Clarendon Press, Oxford, pp 59-68.

\section{Supplementary Material}

The following online material is available for this article:

Table S1 - Allele sizes and frequencies of mapped SSR markers for different barley groups.

Table S2 - Polymorphism Information Content for barley groups using mapped SSR markers.

Table S3 - Clustering of 403 accessions of barley landraces using Un-Weighted Pair Group Arithmetic averages (UPGMA) on the basis of SSRs.

Figure S1 - Principal component analysis of barley landraces based on allele frequencies across mapped SSR markers.

This material is available as part of the online article from http://www.scielo.br/gmb.

\section{Associate Editor: Dario Grattapaglia}

License information: This is an open-access article distributed under the terms of the Creative Commons Attribution License, which permits unrestricted use, distribution, and reproduction in any medium, provided the original work is properly cited. 
Table S1. Allele sizes and frequencies of mapped SSR markers for different barley groups. The number in parentheses below the marker name indicates the number of alleles for that marker.

\begin{tabular}{|c|c|c|c|c|c|c|c|c|}
\hline \multirow[t]{2}{*}{ Loci } & \multirow{2}{*}{$\begin{array}{l}\text { Allele } \\
\text { size } \\
(\mathrm{bp})\end{array}$} & \multicolumn{7}{|c|}{ Allele frequencies } \\
\hline & & Pakistan & India & Iran & Nepal & Iraq & Turkmenistan & Uzbekistan \\
\hline \multirow{7}{*}{$\begin{array}{l}\text { 1H, } \\
\text { Bmag0382 } \\
(7)\end{array}$} & 60 & 0.14 & - & - & - & - & - & - \\
\hline & 66 & 0.46 & 0.39 & 0.07 & 0.24 & 0.05 & 0.88 & 0.8 \\
\hline & 76 & - & - & 0.32 & - & - & - & - \\
\hline & 80 & 0.16 & 0.5 & 0.02 & 0.14 & 0.03 & 0.12 & 0.2 \\
\hline & 88 & - & 0.11 & 0.59 & 0.63 & 0.61 & - & - \\
\hline & 93 & - & - & - & - & 0.32 & - & - \\
\hline & 97 & 0.24 & - & - & - & - & - & - \\
\hline \multirow{8}{*}{$\begin{array}{l}\text { 2H, HVM54 } \\
\text { (8) }\end{array}$} & 60 & - & 0.33 & 0.02 & 0.08 & 0.03 & 0.18 & 1 \\
\hline & 66 & 0.23 & 0.25 & 0.02 & - & - & 0.59 & - \\
\hline & 83 & 0.14 & - & - & - & - & - & - \\
\hline & 88 & 0.12 & - & - & - & - & - & - \\
\hline & 93 & 0.24 & - & - & - & - & - & - \\
\hline & 97 & - & 0.04 & 0.05 & 0.18 & 0.05 & 0.12 & - \\
\hline & 120 & 0.27 & 0.32 & 0.32 & 0.75 & 0.92 & 0.12 & - \\
\hline & 122 & - & 0.07 & 0.59 & - & - & - & - \\
\hline \multirow{11}{*}{$\begin{array}{l}3 \mathrm{H}, \\
\text { Bmag0023 } \\
(11)\end{array}$} & 66 & 0.15 & 0.03 & - & 0.35 & 0.05 & - & - \\
\hline & 72 & 0.13 & - & - & - & - & - & - \\
\hline & 76 & - & - & 0.32 & - & - & - & - \\
\hline & 80 & - & 0.11 & 0.25 & 0.33 & - & - & - \\
\hline & 83 & 0.43 & - & - & - & - & - & - \\
\hline & 88 & - & 0.22 & - & 0.02 & 0.03 & 0.06 & 0.2 \\
\hline & 97 & 0.27 & 0.04 & 0.39 & 0.24 & 0.05 & 0.71 & - \\
\hline & 107 & - & 0.25 & 0.02 & - & - & - & - \\
\hline & 109 & - & 0.09 & 0.02 & 0.06 & - & 0.24 & 0.8 \\
\hline & 116 & - & 0.26 & - & - & - & - & - \\
\hline & 120 & 0.03 & - & - & - & 0.87 & - & - \\
\hline \multirow{5}{*}{$\begin{array}{l}4 \mathrm{H}, \\
\text { Bmag0490 } \\
(5)\end{array}$} & 66 & 0.36 & 0.2 & 0.41 & 0.18 & 0.58 & 0.12 & - \\
\hline & 76 & 0.12 & 0.01 & & 0.31 & 0.05 & - & - \\
\hline & 80 & 0.29 & 0.59 & 0.32 & 0.14 & 0.37 & 0.12 & 0.2 \\
\hline & 88 & 0.23 & 0.13 & 0.02 & 0.37 & - & 0.76 & 0.8 \\
\hline & 97 & - & 0.07 & 0.25 & - & - & - & - \\
\hline \multirow{4}{*}{$\begin{array}{l}5 \mathrm{H}, \mathrm{HvLOX} \\
\text { (9) }\end{array}$} & 51 & - & - & - & - & 0.87 & - & - \\
\hline & 56 & - & - & 0.66 & - & - & - & - \\
\hline & 66 & 0.21 & 0.01 & - & 0.06 & - & - & - \\
\hline & 80 & - & 0.26 & 0.02 & - & - & - & - \\
\hline
\end{tabular}




\begin{tabular}{lcccccccc} 
& 83 & - & 0.04 & - & 0.63 & 0.05 & - & - \\
& 88 & 0.29 & 0.08 & 0.25 & 0.06 & - & 0.65 & - \\
& 97 & 0.26 & - & - & - & - & - & - \\
& 105 & - & 0.26 & - & - & - & - & - \\
$6 \mathrm{H}$, & 120 & 0.24 & 0.34 & 0.07 & 0.25 & 0.08 & 0.35 & 1 \\
Bmag0500 & 62 & - & 0.25 & 0.02 & - & - & - & - \\
$(5)$ & 67 & 0.49 & 0.42 & 0.07 & 1 & 0.66 & 1 & 1 \\
& 75 & 0.12 & 0.07 & 0.59 & - & - & - & - \\
$7 \mathrm{H}, \mathrm{HvID}$ & 80 & 0.39 & - & - & - & 0.34 & - & - \\
$(5)$ & 88 & - & 0.26 & 0.32 & - & - & - & - \\
& 66 & 0.4 & 0.22 & - & 0.02 & 0.89 & 0.06 & - \\
& 80 & 0.38 & 0.62 & 0.66 & 0.18 & 0.05 & 0.12 & - \\
& 88 & 0.17 & 0.01 & - & 0.12 & & 0.06 & - \\
& 97 & 0.06 & 0.11 & 0.02 & 0.37 & 0.05 & 0.76 & - \\
\hline
\end{tabular}


Table S2. Polymorphism Information Content (PIC) for different barley groups using mapped SSR markers

\begin{tabular}{|c|c|c|c|c|c|c|c|c|}
\hline \multirow[t]{2}{*}{ SSR loci } & \multicolumn{7}{|c|}{ Polymorphism Information content (PIC) } & \multirow[b]{2}{*}{ Average } \\
\hline & Pakistan & India & Iran & Nepal & Iraq & Turkmenistan & Uzbekistan & \\
\hline $\begin{array}{l}\text { Bmag0382 } \\
(1 \mathrm{H})\end{array}$ & 0.66 & 0.5 & 0.5 & 0.52 & 0.5 & 0.19 & 0.27 & 0.55 \\
\hline $\begin{array}{l}\text { HVM54 } \\
(2 \mathrm{H})\end{array}$ & 0.77 & 0.71 & 0.5 & 0.37 & 0.1 & 0.95 & 0 & 0.6 \\
\hline $\begin{array}{l}\text { Bmag0023 } \\
(3 \mathrm{H})\end{array}$ & 0.68 & 0.79 & 0.7 & 0.68 & 0.2 & 0.89 & 0.27 & 0.66 \\
\hline $\begin{array}{l}\text { Bmag0490 } \\
(4 \mathrm{H})\end{array}$ & 0.7 & 0.58 & 0.6 & 0.7 & 0.5 & 0.4 & 0.27 & 0.63 \\
\hline $\begin{array}{l}\text { HVLOX } \\
(5 \mathrm{H})\end{array}$ & 0.72 & 0.72 & 0.5 & 0.53 & 0.2 & 0.77 & 0 & 0.61 \\
\hline $\begin{array}{l}\text { Bmag0500 } \\
(6 \mathrm{H})\end{array}$ & 0.58 & 0.66 & 0.5 & 0 & 0.4 & 0 & 0 & 0.45 \\
\hline $\begin{array}{l}\text { HVID } \\
(7 \mathrm{H})\end{array}$ & 0.61 & 0.52 & 0.5 & 0.69 & 0.2 & 0.41 & 0.27 & 0.53 \\
\hline Average & 0.67 & 0.64 & 0.5 & 0.5 & 0.3 & 0.52 & 0.15 & 0.58 \\
\hline
\end{tabular}


Table S3. Clustering of 403 accessions of barley landraces using Un-Weighted Pair Group Arithmetic averages (UPGMA) on the basis of SSRs.

\begin{tabular}{|c|c|c|c|}
\hline Clusters & $\begin{array}{l}\text { Frequency of } \\
\text { accessions for } \\
\text { each cluster }\end{array}$ & $\begin{array}{l}\text { Frequency of } \\
\text { accessions for each } \\
\text { region }\end{array}$ & Accessions codes with their regions in each cluster $(*)$ \\
\hline I & 33 & $33(5)$ & $\begin{array}{l}31034(5), 31035(5), 31022(5), 31030(5), 31033(5), 31028(5), \\
31029(5), 31026(5), 31027(5), 31024(5), 31025(5), 31023(5), \\
31021(5), 31019(5), 31020(5), 31999(5), 31017(5), 31018(5), \\
31015(5), 31016(5), 31011(5), 31013(5), 31009(5), 31010(5), \\
31007(5), 31008(5), 31005(5), 31006(5), 31003(5), 31004(5), \\
31001(5), 31002(5), 31000(5)\end{array}$ \\
\hline II & 38 & $3(2), 33(4), 2(5)$ &  \\
\hline III & 55 & $\begin{array}{l}26(1), 19(2), 6(4), \\
1(5), 2(6), 1(7)\end{array}$ & $\begin{array}{l}30115(1), 30166(1), 30173(1), 30174(1), 30175(1), 30177(1), \\
30179(1), 30191(1), 30192(1), 30193(1), 30202(1), 30205(1), \\
30206(1), 30220(1), 30221(1), 30240(1), 30241(1), 30245(1), \\
30271(1), 30331(1), 30333(1), 30346(1), 30353(1), 30357(1), \\
30358(1), 30360(1), 30704(6), 30724(2), 30729(4), 30731(4), \\
30735(4), 30736(4), 30761(2), 30763(2), 30765(2), 30766(2), \\
30767(6), 30770(2), 30771(2), 30772(2), 30773(2), 30774(2), \\
30775(2), 30776(2), 30777(2), 30778(2), 30781(5), 30782(2), \\
30784(7), 30785(2), 30786(2), 30787(2), 30788(2), 30958(4), \\
30987(4),\end{array}$ \\
\hline IV & 63 & $\begin{array}{l}36(1), 7(2), 1(3) \\
2(4), 13(6), 4(7)\end{array}$ & $\begin{array}{l}30264(1), 30265(1), 30266(1), 30267(1), 30268(1), 30269(1), \\
30272(1), 30279(1), 30285(1), 30286(1), 30287(1), 30288(1), \\
30289(1), 30291(1), 30292(1), 30293(1), 30325(1), 30327(1), \\
30332(1), 30334(1), 30335(1), 30336(1), 30337(1), 30338(1), \\
30339(1), 30342(1), 30347(1), 30350(1), 30351(1), 30352(1),\end{array}$ \\
\hline
\end{tabular}




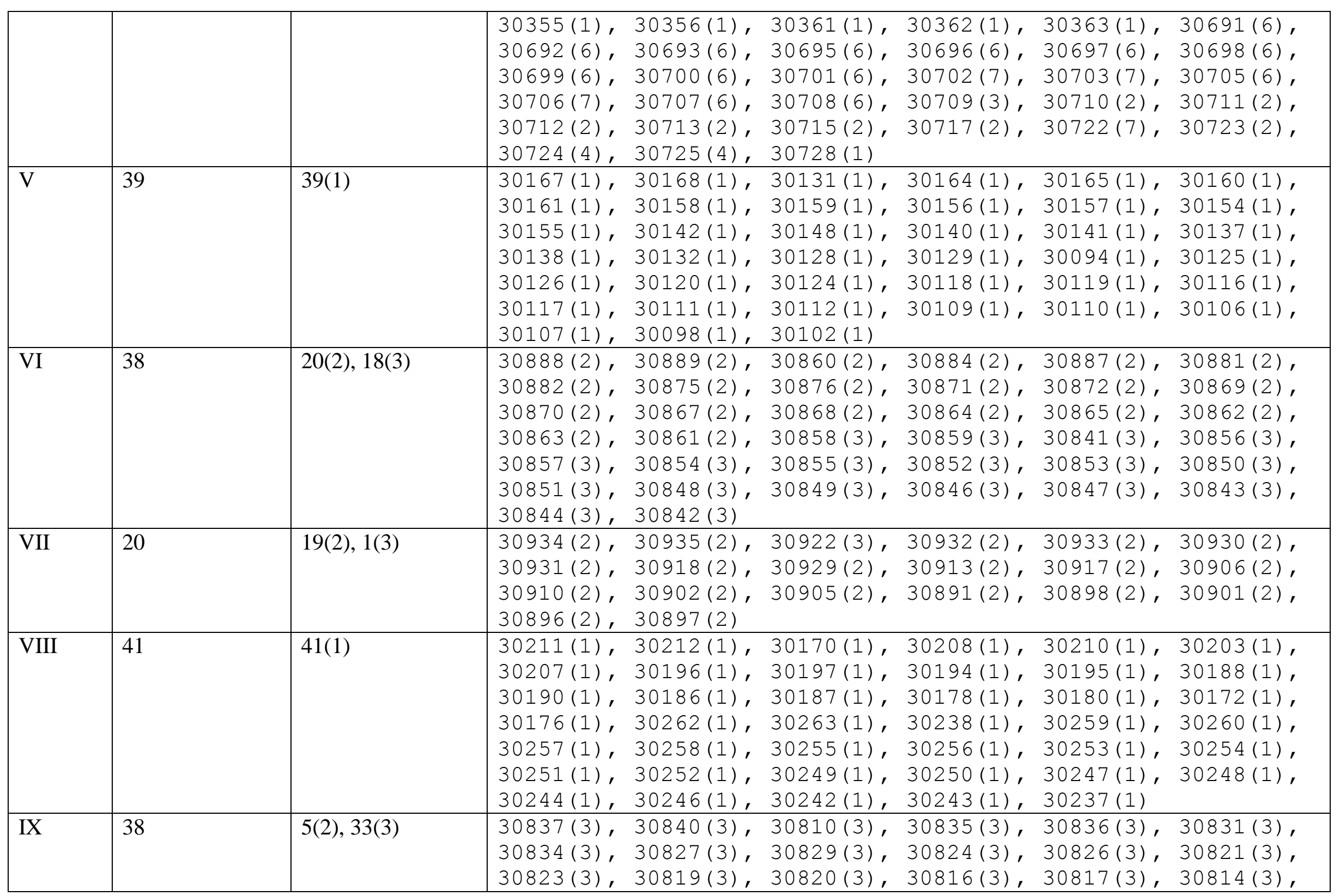




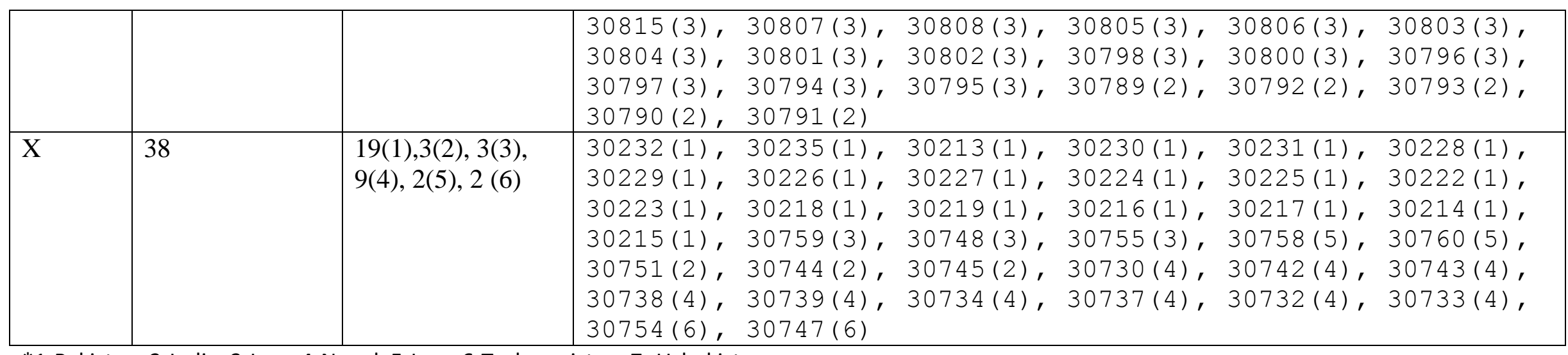

*1-Pakistan, 2-India, 3-Iran, 4-Nepal, 5-Iraq, 6-Turkmenistan, 7- Uzbekistan 




Figure S1 - Principal component analysis of barley landraces based on allele frequencies across mapped SSR markers. 